\title{
Leadership malpractice: exposing the reality underpinning unleaderly behaviour
}

Christopher M. Branson*+ $\odot$, Maureen Marra**

*Australian Catholic University, Brisbane, Australia. Email: christopher.branson@acu.edu.au

** inLeadership Consultancy, Hamilton, New Zealand. Email: mmarra@inleadership.co.nz

Abstract

Keywords

Background. A mounting body of research literature is highlighting the prevalence of serious malpractice by persons in leadership positions. Arguably, too many of those appointed to a leadership position believe that they have the right to act in any way that they choose. They believe that the title of 'leader' affords them the licence to act with little regard for others. But just because a person has been appointed to a leadership position, this does not automatically make them a leader. Nor does it imply that everything they do is leadership. Thus, the impetus for this article is the acknowledgement that it's time to clearly distinguish what truly constitutes leadership from that which is its antithesis - leadership malpractice. Not to do so only allows serious leadership malpractice to become normalised as acceptable leadership activity.

Research Aim. Therefore, the aim of this article is to first use research literature to describe the growing concern about the prevalence of malpractice by persons in leadership positions and then to illustrate how such malpractice can be naturally eradicated when leadership is seen, fundamentally, as a relational phenomenon. The purpose of this article is thus to provide a new theoretical perspective of leadership, one that will help to distinguish between that which is and is not leadership.

Findings. A close inspection of the extremely damaging and injurious outcomes produced by leadership malpractice shows that these mirror those caused by persons with extremely harmful psychosocial disorders. Despite any short-term gains, the research shows that leadership malpractice can ultimately cause serious and enduring poisonous effects on the individuals, families, organizations, communities, and even entire societies they lead. Furthermore, rules, regulations and policies have proven powerless. Seemingly, one cannot mandate true leadership; its manifestation must be inherent within our leadership theory. Practical implications. In response, this article first explores the foundational values, principles and norms underpinning true leadership practice and then presents a new way to understand leadership from a transrelational perspective which naturally eradicates malpractice by those in leadership positions.

Social implications. Given that worldwide research has demonstrated how leadership malpractice causes seriously toxic personal, organisational and social outcomes, this article seeks to provide a theoretical rather than a technical or practical way of redressing this untenable situation. By inference, when leadership is practiced properly, when it is based upon apporpriate foundational values and principles, then malpractice is ended and workplaces become safe, gratifying and productive.

Originality. This article makes a significant contribution to the expanding area of research that is exploring the benefits to be gained by theorising leadership as a relational phenomenon.

leadership, leadership malpractice, transrelational leadership, psychosocial disorders, toxic behaviour, leadership wisdom

\section{INTRODUCTION}

It's time to stop the pretence! It's time to stop calling any activity performed by a person occupying a leadership position as 'leadership' unless it clearly meets the values, principles and norms widely associated with leadership. Not raising the bar on naming what is acceptable leadership practice only devalues and undermines what actually constitutes true leadership. Just because a person has been appointed to a leadership position does not automatically make them a leader. Nor does it imply that everything they do is leadership. It's time to clearly differentiate between what is and what is not leadership practice. Not to do so only allows serious unleaderly behaviour to become normalised as acceptable leadership actions. Unleaderly behaviour is defined as behaviours performed by a person occupying a leadership position that are not only contrary to that expected of a leader but also likely to cause harmful if not abhorrent outcomes for others. At present there are too many highly influential people in leadership positions whose behaviour towards others is anything but leadership and is, thus, causing dire 
consequences. Yet they sell themselves as leaders or are considered by some others to be leaders. Such unleaderly behaviour must be acknowledged as false leadership; it is leadership malpractice and must be stopped by being called for what it really is. To this end, this article will begin by briefly describing the growing prevalence of unleaderly activity by persons in leadership positions. The structural limitations of this article prevent a comprehensive coverage of this unfolding blight upon the important phenomenon of leadership, but the discussion highlights the burgeoning breadth of the issue. Furthermore, this article will show how closely these behaviours align with those persons diagnosed with certain serious psychosocial disorders. Hence, literature from the field of psychology is examined to illustrate the likely impact of such unleaderly activity upon those seeking to be led. This is compared with expanding business research literature that focusses on concerns about employee well-being and stress issues. Following this discussion, a wide array of research literature will be explored to underscore what are generally considered to be the foundational values, principles and norms underpinning true leadership. The article concludes with a brief description of a new way to understand transrelational leadership - which naturally eradicates unleaderly behaviour by those in leadership positions.

\section{THE GROWING PREVALENCE OF UNLEADERLY BEHAVIOUR}

A search of the research literature clearly shows that in today's world it has become common for some in positions of significant influence upon the affairs and wellbeing of others to masquerade as leaders: they claim to be leaders and wrongly label their actions as strong leadership. This situation has evolved despite our leadership theory invariably concentrating on informing readers of what constitutes good, effective, successful leadership attitudes and practices. Arguably, by virtue of their position, some persons assume they are leaders and therefore believe all that they do must be leadership. Moreover, in the absence of judicious critique, such actions can initially produce the façade of good outcomes. But, ultimately, the true and deplorable consequences of such unacceptable practices come to the fore, thereby showing it as being leadership malpractice.

Hence, there is a growing pool of literature describing bad (Schyns \& Schilling, 2013), destructive (Branson \& Marra, 2020; Erickson, Shaw, Murray \& Branch, 2015; Krasikova, Green \& LeBreton, 2013; Lu, Ling, Wu \& Liu, 2012; Shaw, Erickson \& Harvey, 2011; Thoroughgood, Tate, Sawyer \& Jacobs, 2012; Thoroughgood, Sawyer, Padilla \& Lunsford, 2016), abusive (Frieder, Hockwarter \& De Ortentis, 2015; Martinko, Harvey, Brees \& Mackey, 2013; Scheuer, Burton, Barber, Finkelstein \& Parker, 2016; Tepper, 2007) and even toxic (Bhandarker \& Rai, 2018; Fahie, 2019; Lipman-Blumen, 2005; Winn \& Dykes, 2019) leadership. The potential impact of such unleaderly activity is highlighted by Lipmen-Blumen (2005) when describing toxic leaders as those "who by dint of their destructive behaviors and dysfunctional personal qualities generate a serious and enduring poisonous effect on the individuals, families, organizations, communities, and even entire societies they lead" (p.2). What this investigation of the research literature highlights is how easy it can be for a person in a position of authority to appear credible as a leader because people under their authority do not raise concerns or disagreements, because they suppress their opinions for fear of public condemnation and/or employment retribution. A person may seem to have power and authority over others because these people appear to commit and conform to that which they have been assigned. Yet, on closer inspection it is seen that such commitment and conformity result from deeply held feelings of anxiety, apprehension and frustration. What this shows is that the outcomes of leadership malpractice can produce what resembles cooperation and concurrence when in fact this has resulted from fear, dejection, despair and pessimism, the very antithesis of what leadership should engender in others. However, this investigation of the research literature also highlights that the serious issue of leadership malpractice is being largely ignored. It appears that a long shadow of transactional leadership lingers on despite Burns's (1978) comprehensive description of its inadequacies and inappropriateness some 40 years ago. According to Burns's widely accepted description, leadership practice throughout the first 75 years of the twentieth century was transactional because employees were paid to do what they were told to do by their leader. Transactional leaders are firm in their opinion that it is solely their responsibility to control and direct employee performance through reward and coercive measures so as to produce the desired output. They believe they largely know what is best for the organization and so institute a predominantly exclusive, top-down, controlled and inflexible working environment. In contrast, Burns (1978) advocated for transformational leadership to replace its outdated and largely ineffectual predecessor of transactional leadership. Transformational leadership is associated with employees becoming better at what they do - being 'transformed' - due to the leader's actions. Ideally, the attention of the transformational leader is on looking after the needs and interests of the employee, whereas the attention of the transactional leader is on looking after the quality of the work that was produced. Regardless of the largely universal endorsement of Burns's compelling promotion of transformational leadership practices, this was tempered to some degree by the realization that, in certain exceptional circumstances, there is still a need for transactional leadership. In other words, the introduction of the concept of 
transformational leadership only minimized, and did not eradicate, transactional leadership practices. Hence, it remains far too easy for the reality of leadership malpractice to be erroneously dismissed as simply a contemporary application of an assertive version of transactional leadership: that is, just a strong leadership style.

Arguably, this critically essential outcome will only be achieved if the reality underpinning such unwarranted malpractice is understood from essentially a psychological rather than a leadership perspective. Understanding such unleaderly activity as an outcome of a personality disorder rather than that of exaggerated transactional leadership lays bare the urgency of seeing this for what it truly is; it also emphasises the dire need to redefine what truly constitutes leadership.

\section{INSIGHTS FROM PSYCHOLOGY}

In parallel with the aforementioned leadership research literature, there has been research into the prevalence of seriously destructive leadership malpractice from a psychological perspective inclusive of psychopathy (Barelds, Wisse, Sanders \& Laurijissen, 2018; Landay, Harms \& Credé, 2019; Mathieu, Neumann, Hare, \& Babiak, 2014; Vergauwe et al., 2021), narcissism (Erkutlu \& Chafra, 2017; Fatfouta, 2019) and megalomania (Seifried, 2018; Seifried, Katz, \& Pfleegor, 2015). Psychopathy is a clinical construct defined by a cluster of personality traits and characteristics including grandiosity, egocentricity, deceptiveness, shallow emotions, lack of empathy or remorse, irresponsibility, impulsivity, and a tendency to ignore or violate social norms (Mathieu et al., 2014). Hence, corporate psychopathy pertaining to a leader's personality disorder manifests as an incapacity to develop positive interpersonal relationships, to share ideas, and to give credit to others (Landay, Harms \& Credé, 2019). Furthermore, these authors add that leaders displaying corporate psychopathy are prone to regularly show inequitable treatment of staff, deceptiveness, immodesty, inability to accept blame, unpredictability and impulsiveness, and overt aggression.

Similarly, narcissism is a personality disorder that presents as personal traits encompassing grandiosity, arrogance, selfabsorption, entitlement, fragile self-esteem, and hostility (Kranefeld \& Blickle, 2022). Thus, the visions, plans, and actions of narcissistic leaders are synonymous with these personality traits (Erkutlu \& Chafra, 2017). For example, because of their need for grandiosity, narcissistic leaders regularly self-promote and self-nominate, resist advisers' suggestions, take more credit for successes than they are due, and blame others for their own failures and shortcomings (Fatfouta, 2019). Moreover, they readily employ deception, manipulation, and intimidation in order to take advantage of others or to secure leadership positions even when they are underqualified (Blickle, Schütte \& Genau, 2018). Although their need for personal glory can sometimes enable a narcissistic leader to initiate a beneficial innovation (Fatfouta, 2019), even so, they will invariably leave damaged organisational systems and relationships in their wake due to their notoriously poor judgement, abusive managerial style, and unprofessional personal conduct (Kranefeld \& Blickle, 2022).

Then there is the megalomaniac: the 'leader' with a psychological disorder which manifests as a delusionary obsession with power and personal greatness. When present in the psychological makeup of a leader, megalomania causes the person to use their position to gain personal benefit despite detrimental impact on others (Seifried et al., 2015) because they are excessively arrogant, have a heightened sense of entitlement, and an obsession with being acknowledged for greatness and prestige (Rosenthal \& Pittinsky, 2006). At their very core, the megalomaniac leader is self-absorbed in their own self-admiration (Barelds et al., 2018). Megalomaniacal leaders have an exaggerated self-concept such that they believe they are capable of doing what nobody else can do (Seifried, 2018). At the same time, they will expect social validation of their superiority and greatness, which they associate with being in a position of power. However, although they show great self-confidence, they lack empathy, sensitivity and social awareness.

As can be seen from these brief descriptions, there are common characteristics among these three psychological disorders but there are key differences too. For example, although psychopathy and narcissism share similar characteristics, narcissism intensifies these and so produces worse outcomes for those being led. The narcissistic leader is a person on a quest for power and control, who uses the love and admiration of others as a tool to dominate and manipulate, and who goes about all of this thinking that it is their right and that they are justified (Erkutlu \& Chafra, 2017; Fatfouta, 2019). Thus, there is no guilt, no apology, and no remorse no matter the outcome. While the difference between a narcissist and a megalomaniac is that a megalomaniac is generally consumed by a need to feel superior to everyone else, a narcissist is more concerned with having a feeling of excessive self-worth.

Be these differences what they may, the essential task is to recognise the seriously deleterious consequences for others caused by persons in leadership positions having one or more of these personality disorders or some of these harmful behaviours. First, it is important to highlight how difficult it can be to identify such a leader because they are quite able to present a façade of normalcy. They can appear suitable leaders at times because of certain characteristics related to their disorder including cool- 
headedness, risk taking and strong persuasion skills (Sheehy and colleagues, 2020). They can appear to be suave, successful and competent, and often dress to impress. Such characteristics are described as masks used for duping the unwary and sophisticated alike. In contrast to these masks, the research evidence also shows that these leaders can be particularly ruthless, conscience-free managers (not leaders) who are largely motivated by greed and self-aggrandisement. They excel in recognising those others who they need in order to personally benefit and those others who can make their lives difficult, as well as those others who they can intimidate, disregard and ignore. As leaders these persons often present as highly intelligent and well-educated but enact excessive managerialism underpinned by suppression, seduction, aggressive competition and the overt and strategic application of power and authority.

Clearly, despite their personality disorder these persons are able to gain senior leadership appointments. This is because, as Costello and colleagues (2018) observe, such personality disorders can present with appealing strengths including 1) charming and manipulative traits; (2) a seemingly productive style of leadership whereby they readily take charge, make decisions, and get others to do what needs to be done; (3) a lack of empathy which can be misinterpreted as confidence, strength and calm in difficult circumstances; and (4) ignoring rules to get things done and so being viewed as innovative and trailblazing. In addition, Sheehy and colleagues (2020) explain how one of the reasons organisations may appoint such a person to a key leadership position comes from two pivotal issues: the dire needs of an organisation at risk and an incorrect view of leadership. They go on to describe how the nexus between these two issues occurs when there is the view that, firstly, the organisation is recognised as underperforming if not dysfunctional and, therefore, needs a far more ruthless approach to introducing change. It is presumed that the new leader needs to be able to deal harshly or unempathetically with the employees in order to create the desired change. Secondly, it is incorrectly assumed that a tough leader is good for productivity and performance because the solution to underperformance is the single-minded actions of a remorseless leader.

However, research has shown that although these persons as leaders might initially seem to achieve positive outcomes for the organisation, ultimately, they are likely to inflict considerable harm including increased organisational dysfunction, diminished employee well-being, loss of high performing employees, decreased productivity and profitability, and possibly serious legal ramifications. For example, research in the United Kingdom found that 35\% of all workplace bullying was associated with the presence of such leaders (Boddy, 2011). Similarly, research in Australia concluded that around $26 \%$ of all bullying is accounted for by $1 \%$ of the employee population most of whom have one or more of these personality disorders (Boddy, 2014). Sheehy and colleagues (2020) describe how organisational decline and undesirable legal consequences arise because such leaders routinely engage in manipulation of people and systems, initiate high-risk decisions and are prone to unethical and even criminal behaviours, thereby causing irreparable damage to the health and wellbeing of the organisation and its employees.

\section{UNMASKING UNLEADERLY PRACTICES}

However, the intention of this discussion is not simply to suggest that leadership malpractice is solely confined to the extreme cases of psychopathy, narcissism and megalomania but, rather, to focus attention on what can be considered to be unleaderly behaviours. To this end, these unleaderly behaviours include the personality characteristics of an obsession with being acknowledged for greatness and prestige, a heightened sense of entitlement, a strong desire to be in total control, a tendency to take more credit for successes than they are due and blame others for their own failures and shortcomings, a propensity for deceptiveness and unfairness, impotence in creating positive working relationships, a lack of empathy or remorse, being prone to making irresponsible and impulsive decisions, and a tendency to ignore or violate social norms in order to meet their own self-interests or to subjugate others. All of these create partisanship and completely undermine trust and harmony throughout the workplace. These are the behaviours that must not be practised by leaders. Furthermore, should a person in a leadership position be enacting some or many of these behaviours, then it can be rightly claimed that this is leadership malpractice. Therefore, it is time to unmask leadership malpractice by such unsuitable persons. No longer can such destructive, toxic, unleaderly behaviours of a person in a leadership position be ignored or dismissed as simply an extreme or exaggerated style of transactional or managerial leadership because the serious ill-effects are suffered by the workers and the organization and not by the perpetrator. Moreover, no end justifies such means. No initial benefit to the organization can ever be justified if it is achieved at the expense of the wellbeing of employees.

But it is clear that simply describing these unethical, intolerable, appalling and destructive practices is not enough, for such descriptions have been circulating for nearly 20 years and the problem is getting worse. Thus, we argue that the only way to curb such blatant leadership malpractice is to redefine what truly constitutes leadership; to definitively articulate the principles and practices that unequivocally distinguish contemporary leadership from all other fallacious forms of its enactment. This 
will be achieved by first reviewing the foundational literature aligned with our modern understanding of leadership and then to describe how our new theory of organisational ecology can naturally and readily engender true leadership for today's world.

\section{THE FOUNDATIONS OF MODERN LEADERSHIP}

As alluded to earlier in this article, the initial foundations of our current leadership theory were inaugurated by James MacGregor Burns's (1978) seminal book Leadership, in which he established the distinction between transactional and transformational leadership. Burns's key message was in arguing that transactional leadership has had its day and it was time to move on to transformational leadership. Importantly, it is the fundamental principles of transactional leadership that align with those of a corporate psychopath, but not to the same extreme extent. Corporate psychopaths tend to exaggerate the detrimental characteristics of transactional leadership. Yet, sadly, this similarity with transactional leadership provides a degree of credibility and justification for the practices of corporate psychopaths. Thus, in developing a more conversant understanding of the obligatory foundations of modern leadership it is imperative to recall Burns's key features of transformational leadership, which unequivocally distinguish it from transactional leadership and, correspondingly, demolish the leadership façade practiced by corporate psychopaths.

When promoting the need for the new transformational approach to leadership, Burns argued that leadership is better served if it is focused on transforming those being led. In order to transform the people, the leader must concentrate on making those being led more knowledgeable and skillful about their work so as to make it more meaningful and satisfying. Burns's view was that once the person feels capable in doing work that is more meaningful and satisfying to them, they will naturally perform their work more efficiently and effectively. Essentially, the application of a transformational approach to leadership introduced the need for the person in the leadership position to be far more considerate and inclusive of the needs of those being led. For Burns (1978), a fundamental requirement of leadership is that

leaders address themselves to followers' wants, needs, and other motivations, as well as their own, and thus they serve as an independent force in changing the makeup of the followers' motive base through gratifying their motives. (p.20, italics in original text)

More specific to the inappropriate actions of corporate psychopaths, Burns warns that the

test of leadership in all its forms is the realization of purpose measured by popular needs manifested in social and human values. Leaders can operate off the "skin" of public opinion - off surges of trending opinion, the applause of idolizing spectators, the bubbling up of passing social and political fads, trumped up foreign crises, and exaggerated dangers to national security - without recognizing the persisting, widespread, and intensive needs and goals that motivate followers and are there for the evoking by leaders. (p.251)

The challenge for the leader, according to Burns, is to ensure that the needs of those being led, and not self-interests, are influencing their leadership decisions and behaviours. Simply stated, what distinguishes true leadership practice from leadership malpractice is that the needs of those being led, and not the leader's interests, are the primary departure point for the leader's actions. This understanding is pivotal in denouncing the claims to leadership by corporate psychopaths who use overtly assertive behaviours, coercive policies and actions, charismatic appeal or misleading information to manipulate the emotions and beliefs of others for their own self-interests. Furthermore, Burns's transformational leadership theory encompassed the argument that the authentic authority of a leader is made manifest through relationships. According to Burns, 'The most powerful influences consist of deeply human relationships in which two or more persons engage with one another" and, thus, for a leader, the "arena of power is no longer the exclusive preserve of a power elite or an establishment or persons clothed with legitimacy. Power is ubiquitous; it permeates human relationships' ( $p .15)$. True or authentic leadership practice incorporates 'power with' others. Leadership malpractice asserts 'power over' others.

Sadly, while Burns's dichotomous categorization of leadership as being either transactional or transformational attracted worldwide attention, his a priori view of the centrality of relationships in the practice of leadership gained little attention. Essentially, rather than embracing transformational leadership as an entirely new phenomenon with fundamentally different foundational values and principles, and therefore uniquely different practices, its enactment was largely confined to simply the behaviours of leaders. Arguably, most leaders stayed in total control but applied far less overtly coercive ways to manipulate 
others to do their bidding. Charm and charisma can be misused to manipulate, suppress and control. Rosenthal and Pittinski (2006) describe how easy it is for those in leadership positions with those serious personality disorders described above to exploit their personal charismatic charm in order to convince those they have responsibility to lead to not only buy into the suppressive managerial processes but also to shoulder the blame when plans go wrong.

Ultimately, Burns's introduction and promotion of transformational leadership as the preferred style did not eradicate the likelihood that persons with seriously inappropriate personality disorders would gain leadership positions. Hence, it is unsurprising that subsequent leadership theories sought to emphasize an ethical expectation for leadership practice. For example, Hodgkinson (1978) called for the restoration of a moral foundation in leadership theory. A few years later, Greenfield (1981) and Foster (1986) emphasized the need for further study into the ethical and moral aspects of leadership. Begley (2003) described the concept of authentic leadership as a "professionally effective, ethically sound, and consciously reflective" (p.1) form of leadership. Also, when promoting moral leadership, both Sergiovanni (1992) and Starratt (1994) shared the view that the leader must closely consider what is significant, what is right and what is worthwhile in all of their decision-making activities and that commitment to such ethical and moral behaviour elevates the leader above mere pragmatics or expediency so as to raise their moral reasoning in order to transform their self and those they lead. Also, Day (2000) argued that the fulfillment of a truly transformational approach to leadership was depended upon a far more 'values-led' commitment than initially considered due to the ever-increasing influence of change and uncertainty upon the role of the leader.

It was assumed that, if wholeheartedly enacted, this ethically strengthened transformational leadership perspective would prevent leadership malpractice. The assumption that leadership is resolutely committed to ethically informed transformational practice would naturally eradicate opportunities for those persons seeking self-interest and self-glorification though grossly destructive dominating, coercive, and manipulative ways. Instead, this form of transformational leadership would only allow those persons to become leaders who are able to influence others through persuasion and personal commitment, who seek the common good, who readily put the needs of others before their own, who can empathise with and care for others, and who naturally act with fairness, justice and equity. But, again, this assumption has not reflected reality (Boddy, 2011, 2014; Sheehy et al., 2020).

Arguably, today's leadership theory, along with many unacceptably outdated leadership understandings, still allow those persons with serious personality disorders to not only become leaders but also to implement practices that garner endorsement from some others as acceptable leadership behaviour. As long as this leadership theory and leadership understandings remain focussed on what the leader does, then seriously destructive leadership malpractice will persist. Leadership must be judged by its intent and not its actions. As has been clearly described previously, actions can be misleading because the actions of a person with wilful intent can sometimes appear acceptable. Focussing on the person's intention - their purpose and its ultimate significant outcomes - steers leadership away from an essentially individualistic process and towards an imperative collective endeavour. Leadership malpractice is leader-centric; leadership, its true self, is relationship-based.

\section{RELATIONSHIP-BASED LEADERSHIP}

As we have argued previously (Branson \& Marra, 2019), complexity theory urges us to acknowledge the daily presence of surprise and emergence. Not only do unanticipated things regularly happen but also new ways of successfully dealing with these happenings can unexpectedly emerge. Moreover, no matter how determined we are to control our environment in order to maintain predictability and security, surprise and predicaments invariably arise. Hence, it is argued that today's leaders cannot totally prevail over an organisation's internal environment or control future outcomes, as traditional leadership research suggested. If leaders cannot control the organisation's internal environment or predict and manipulate the future state of the external environment, they need to acknowledge and accept that this emerges from the interactions among people throughout the organisation. Much more than what the leader might choose to do, it is the people in the organisation who bring about what will happen in the organisation. It is through the willing involvement of the people that the leader is able to enact their leadership. This is a view contrary to the common taken-for-granted, but misguided, belief that a person can immediately enact leadership in whatever way they wish once they are appointed to a leadership role. The formal acknowledgement of a person's public designation as a leader is also usually encapsulated in the belief that this person occupies a particularly important and essential role, which is distinguishable and discrete from that of those they are to lead. Moreover, the desired outcomes and expected actions of the role holder are often captured in a role statement to which the leader can be held accountable. Thus, both the establishment of the role and the description of the role promote a detached, linear management view of the affiliation between the leader and those they are to lead.

Recent advances in sociology call into question these common assumptions associated with 'roles' and prefer to label these as 'positions' (Davies \& Harré, 1999; Harré \& Moghaddam, 2003; Harré \& Slocum, 2003). Seeing the responsibility of leadership 
as a role gives the impression that the nature of its enactment, and how others experience it, is the prerogative of the role holder and their line managers. In this sense, a role has the potential to be imposed. However, the reality of imposed roles rarely equates with the ideal. The natural tendency of those being led is to use whatever subtle or explicit means they can to cause the leader to modify their style of leadership to that of a more acceptable form. Hence, there are no real leadership roles, but rather, only negotiated leadership positions. In other words, in order to become a leader, the person must realise that the genesis of their leadership is in the everyday human interactions they have with each and every person they have the responsibility to be leading (Crevani, Lindgren \& Packendorff, 2010).

Leadership as a 'position' acknowledges that the practice and outcomes of leadership evolves largely in response to the effects generated by their interactions with those they are leading (Harré \& Van Langenhove, 1999). Thus, the leader is enacting a 'position' rather than performing a 'role'. Positions are socially shaped behaviours around patterns of mutually accepted beliefs, needs and expectations. Roles, on the other hand, are prescribed behaviours that are more explicit, precise, individualistic, and practical in formation and nature, and often reflect an ideal rather than the reality. To become a leader, the person needs to first negotiate with those they are leading, to build a mutually understood and accepted view of what the inherent responsibilities of the leadership position are, and how it may be best performed (Harré \& Moghaddam, 2003). As a negotiated position, the ultimate image of leadership is co-constructed through the realisation and consolidation of mutually accepted values, beliefs and expectations. Furthermore, Davies and Harré (1999) posit that the concept of position readily embraces the dynamic aspects of externally structured and imposed human engagements 'in contrast to the way in which the use of "role" serves to highlight static, formal and ritualistic aspects' (p. 32).

Essentially, leadership is constructed in the common daily social interactions between the nominated leader and those they are tasked with leading. This implies that the commonly held view of individualism in leadership needs to be challenged. Rather, leadership is co-constructed, such that the effectiveness of a leader cannot be measured by their achievement of certain practical competencies but more on how well they are able to establish mutually beneficial relational processes with those they are leading. These processes are authentically human in nature and cannot be reduced to mechanical, technical or clinical intentions designed to achieve the self-interests of the supposed leader. They "are characterized by a social flow of interacting and connecting whereby organizations, groups, leaders, leadership and so forth are constantly under construction and re-construction" (Crevani, Lindgren \& Packendorff, 2010, p. 79). Thus, leadership is not formed from key, or significant or prescribed actions initiated in particular circumstances in certain ways or at given times by a person appointed to a leadership role. Declaring a vision or implementing a policy or publicizing a new development or presenting an annual budget and so forth have little to do with the person's leadership reputation. Quite the opposite - the acceptance of a person as a leader and judgements about them as a leader are things that are incrementally formed as they move around the organization and interact with individuals and groups (Lichtenstein \& Plowman, 2009). Those being led are slow to judge the leadership capacity of the formal leader. They need to trust that what they first see is not only acceptable, but also authentic and typical. They need to firmly believe that the formal leader can be trusted and is reliable in their leadership behaviours. The person can only enact true leadership when, and only when, they are accepted as the leader. This means that 'leadership is not a one-way influence process but rather a reciprocal influence relationship. . . . As in any other relationship, both sides contribute to its formation, nature and consequences' (Shamir, 2011, p. 310). Essentially, the relational cornerstone of leadership is the reciprocal and dynamic interaction process between the formal leader and those to be led - and that necessitates leadership wisdom.

\section{LEADERSHIP WISDOM}

As described in far more detail elsewhere (Branson and Marra, 2021), leadership wisdom is the cumulative outcome of analytical intelligence, practical intelligence, emotional intelligence, and intuitive intelligence. Indeed, the person must possess all four intelligences in order to consistently display leadership wisdom. Analytical intelligence implies that the person is able to understand, analyse, interpret, and synthesise the explicit, objective, rational sources of knowledge associated with their workplace. In contrast, the genesis of practical intelligence is in work-related know-how and in-depth cognitive knowledge associated with how the workplace functions and how they can best contribute to this functioning. The third essential component of leadership wisdom is that of emotional intelligence. Actions emanating from emotional intelligence must be seen to be deeply sincere and authentic. Such a stance is not based upon some externally imposed edict, obligation, commandment or mandate but, rather, is personally formed through the awareness and synthesis of one's context, of human nature shaped from deeply knowing one's self, of the needs of others, and of the essential values and beliefs that will maximize the common good. The final essential component of wisdom is that of intuitive intelligence. Leaders in today's organisational climate are constantly 
working within an environment that is changing, becoming more complex, and increasingly filled with uncertainty. In times of ambiguity, intuitive intelligence enables leaders to, without conscious awareness, both discover and then defend an analysis and interpretation of exceedingly large and complex data. They can see, describe, and justify patterns, or heuristics, in such data that is, initially, beyond the view of others.

Those persons prone to consistent acts of leadership malpractice clearly lack emotional intelligence, which drastically constrains and destructively infuses any semblance of analytical, practical or intuitive intelligence that they possess. Their potential for analytical, practical and intuitive intelligences is trashed by a dominating unethical commitment to self-centeredness and selfgrandeur. Only a wise leader knows that the workplace is its people and not a vehicle for achieving toxic self-interests. Hence, it is time to stop calling anyone enacting leadership malpractice a leader. They are not leaders. We must not in any way dignify their seriously destructive unleaderly behaviour by referring to them as a leader.

\section{CONCLUSIONS}

Although the advent of transformational leadership in 1978 aimed to move the leader's primary concern away from selfinterest to the needs of those being led, it failed to contest the leader's decision-making domination. While it did increase the expectation of the leader to be concerned about the people as well as the profits, transformational leadership still left the leader as the principal arbitrator in determining what or who needed to transform and how this was to be achieved. Essentially, this new perspective attempted to change leadership theory without simultaneously changing organizational culture. Hence, the culture, in which the leader maintains control, and had the final say, persisted. Simply, how transformation was to unfold remained the leader's prerogative, thereby allowing for leader self-interest to continue to be pursued. Regrettably, opportunities for leadership malpractice can easily arise wherever leader self-interests are tolerated. In other words, the introduction and promotion of transformational leadership failed to prevent leadership malpractice. However, when the presence of leadership is determined by the quality of the relationships its practices engender, rather than the types of practices it enacts, then leadership malpractice cannot gain a foothold.

Thus, in our recent publication, Leadership in higher education from a transrelational perspective (2018), we strongly claim that leadership must be understood as fundamentally a relational phenomenon. Indeed, within this text we argue that 'leadership is best understood as a transrelational phenomenon as its essence is to move others, the organization and the leader to another level of functioning by means of relationships' (p.49). Should the actions of a person in a leadership position selfishly, willfully or intentionally jeopardize their relationship with those being led, then this must be judged as leadership malpractice and their continuation in this position should be challenged accordingly and the appropriate action taken. When mutually beneficial relationships become the manifestation of leadership, there is no place for any form of unleaderly behaviour.

\section{REFERENCES}

Barelds, D. P. H., Wisse, B., Sanders, S., \& Laurijissen, L.M. (2018). No regard for those who need it: The moderating role of follower selfesteem in the relationship between leader psychopathy and leader self-serving behavior. Frontiers in Psychology, 9(1281), 1-12.

Begley, P. T. (2003). In Pursuit of authentic school leadership practices (pp. 1-12). In P. T. Begley \& O. Johansson (Eds.), The ethical dimensions of school leadership. Dordrecht, Netherlands: Kluwer Academic Publishers.

Blickle, G., Schütte, N., \& Genau, H.A. (2018). Manager psychopathy, trait activation, and job performance: a multi-source study. European Journal of Work and Organizational Psychology, 27(4), 450-461.

Bhandarker, A., \& Rai, S. (2018). Toxic leadership: Emotional distress and coping strategy. International Journal of Organization Theory \& Behavior, 22(1), 65-78.

Boddy, C. R. (2011). The corporate psychopaths theory of the global financial crisis. Journal of Business Ethics, 102(2), 255-259.

Boddy, C. R. (2014). Corporate psychopaths, conflict, employee affective well-being and counterproductive work behaviour. Journal of Business Ethics, 121(1), 107-121.

Branson, C. M., \& Marra, M. (2019). Leadership as a relational phenomenon: What this means in practice. Research in Educational Administration and Leadership, 4(1), 81-108.

Branson, C. M., \& Marra, M. (2020). An exploration of the emotional impact of false leadership (pp.81-94). In R. Dorczak \& A. SzczudlińskaKanoś (Eds.), Emotions in leadership. Krakow, Poland: Jagiellonian University.

Branson, C. M., \& Marra, M. (2021). A new theory of organizational ecology, and its implication for educational leadership. London: Bloomsbury. 
Branson, C. M., Marra, M., Franken, M., \& Penney, D. (2018). Leadership in higher education from a transrelational perspective. London: Bloomsbury.

Burns, J. M. (1978). Leadership. New York, NY: Harper and Row.

Clarke, J. (2005). Working with monsters. How to identify and protect yourself from the workplace psychopath. Sydney: Random House, Sydney.

Coid, J., Yang, M., Ullrich, S., Roberts, A., \& Hare, R. D. (2009). Prevalence and correlates of psychopathic traits in the household population of Great Britain. International Journal of Law and Psychiatry, 32, 65-73.

Costello, T. H., Unterberger, A., Watts, A. L., \& Lilienfeld, S. O. (2018). Psychopathy and pride: Testing Lykken's hypothesis regarding the implications of fearlessness for prosocial and antisocial behavior. Frontiers in Psychology, 9(185), 1-13.

Crevani, L., Lindgren, M., \& Packendorff, J. (2010). Leadership, not leaders: On the study of leadership as practices and interactions. Scandinavian Journal of Management, 26(1), 77-86.

Davies, B., \& Harré, R. (1999). Positioning and Personhood. In R. Harré and L. Van Langenhove (eds), Positioning Theory, (pp.32-52). Oxford, England: Blackwell Publishers.

Day, C. (2000). Beyond transformational leadership. Educational Leadership, 57(7), 56-59.

Erickson, A., Shaw, B., Murray, J., \& Branch, S. (2015). Destructive leadership: Causes, consequences and countermeasures. Organizational Dynamics, 44, 266-272.

Erkutlu, H., \& Chafra, J. (2017). Leader narcissism and subordinate embeddedness: The moderating roles of moral attentiveness and behavioral integrity. EuroMed Journal of Business, 12(2), 146-162.

Fahie, D. (2019). The lived experience of toxic leadership in Irish higher education. International Journal of Workplace Health Management, 13(3), 341-255.

Fatfouta, R. (2019). Facets of narcissism and leadership: A tale of Dr Jekyll and Mr Hyde. Human Resource Management Review, 19,1 -12.

Foster, W. (1986). Paradigms and promises: New approaches to educational administration. Buffalo, NY: Prometreus.

Frieder, R. E., Hockwarter, W. A., \& De Ortentis, P. S. (2015). Attenuating the negative effects of abusive supervision: The role of proactive voice behaviour and resource management ability. The Leadership Quarterly, 26, 821-837.

Greenfield, T. B. (1981). Can science guide the administrator's hand? In T.T. Aoki (Ed.), Rethinking Education Modes of Inquiry in the Human Sciences. Edmonton, AL: University of Alberta Press.

Harré, R. \& Slocum, N. (2003). Disputes as Complex Social Events: On the Uses of Positioning Theory. In R. Harré and F. Moghaddam (eds.), The Self and Others: Positioning Individuals and Groups in Personal, Political, and Cultural Contexts, (pp.123-36). Westport, CT: Praeger Publishers.

Harré, R., \& Moghaddam, F. (2003). Introduction: The Self and Others in Traditional Psychology and in Positioning Theory. In R. Harré and F. Moghaddam (eds.), The Self and Others: Positioning Individuals and Groups in Personal, Political, and Cultural Contexts, (pp.1-11). Westport, CT: Praeger Publishers.

Harré, R., \& van Langenhove, L. (1999). The Dynamics of Social Episodes. In R. Harré and L. van Langenhove (eds.), Positioning Theory, (pp.1-13). Oxford, England: Blackwell Publishers.

Hodgkinson, C. (1978). Towards a philosophy of administration. Oxford: Blackwell.

Kernberg, O. F. (1989). Narcissistic personality disorder in childhood. Psychiatric Clinics of North America, 12, 671-694.

Kranefeld, I., \& Blickle, G. (2022). Disentangling the relation between psychopathy and emotion recognition ability: A key to reduced workplace aggression? Personality and Individual Differences, https://doi.org/10.1016/j.paid.2021.111232

Krasikova, D. V., Green, S. G., \& LeBreton, J. M. (2013). Destructive leadership: A theoretical review, integration, and future research agenda. Journal of Management, 39(5), 1308-1338.

Landay, K., Harms, P. D., \& Credé, M. (2019). Shall we serve the dark lords? A meta-analytic review of psychopathy and leadership. Journal of Applied Psychology, 104(1), 183-196.

Lichtenstein, B. B., \& Plowman, D. A. (2009). The leadership of emergence: A complex systems leadership theory of emergence at successive organizational levels. The Leadership Quarterly, 20(4), 617-630.

Lipmen-Blumen, J. (2005). Toxic leadership: When grand illusions masquerade as noble visions. Leader to Leader, Spring, 1-16.

Lu, H., Ling, W., Wu, Y., \& Liu, Y. (2012). A Chinese perspective on the content and structure of destructive leadership. Chinese Management Studies, 6(2), 271-283.

Maccoby, M. (2000, January-February). Narcissistic leaders: The incredible pros, the inevitable cons. Harvard Business Review, 69-77.

Martinko, M. J., Harvey, P., Brees, J. R., \& Mackey, J. (2013). A review of abusive supervision research. Journal of Organizational Behavior, 34, 120-s137.

Mathieu, C., Neumann, C., Hare, R. D., \& Babiak, P. (2014). A dark side of leadership: Corporate psychopathy and its influence on employee well-being and job satisfaction. Personality and Individual Differences, 59, 83-88. 
Neumann, C. S., \& Hare, R. D. (2008). Psychopathic traits in a large community sample: Links to violence, alcohol use, and intelligence. Journal of Consulting and Clinical Psychology, 76, 893-899.

Rosenthal, S. A., \& Pittinsky, T. L. (2006). Narcissistic leadership. The Leadership Quarterly, 17, 617-633.

Scheuer, M. L., Burton, J. P., Barber, L. K., Finkelstein L. M., \& Parker, C. P. (2016). Linking abusive supervision to employee engagement and exhaustion. Organization Management Journal, 13(3), 138-147.

Schyns, B., \& Schilling, J. (2013). How bad are the effects of bad leaders? A meta-analysis of destructive leadership and its outcomes. The Leadership Quarterly, 24, 138-158.

Seifried, C. (2018). The use of sport in North Korea: An illustrative case of megalomania as a style of destructive leadership. Journal of Contemporary Athletics, 12(3), 191-207.

Seifried, C., Katz, M., \& Pfleegor, A. (2015). Megalomaniac or narcissist? Re-examining the leadership style of Huey P. Long through sport. Journal of Sport History, 42: 401-420.

Sergiovanni, T. (1992). Moral leadership: Getting to the heart of school improvement. San Francisco: Jossey Bass.

Shamir, B. (2011). Leadership takes time: Some implications of (not) taking time seriously in leadership research. The Leadership Quarterly, 22(2), 307-315.

Shaw, J. B., Erickson, A., \& Harvey, M. (2011). A method for measuring destructive leadership and identifying types of destructive leaders in organizations. The Leadership Quarterly, 22, 575-590.

Sheehy, B., Boddy, C., \& Murphy, B. (2020). Corporate law and corporate psychopaths. Psychiatry, Psychology and Law, 0(0), 1-29. https:// dx.doi.org/10.1080/13218719.2020.1795000

Starratt, R. J. (1994). Building an ethical school: A practical response to the moral crisis in school. London: Falmer Press.

Tepper, B. J. (2007). Abusive supervision in work organizations: Review, synthesis, and research agenda. Journal of Management, 33(3), 261-289.

Thoroughgood, C. N., Tate, B. W., Sawyer, K. B., \& Jacobs, R. (2012). Bad to the bone: Empirically defining and measuring destructive leader behaviour. Journal of Leadership \& Organizational Studies, 19(2), 230-255.

Thoroughgood, C. N., Sawyer, K. B., Padilla, A., \& Lunsford, L. (2016). Destructive leadership: A critique of leader-centric perspectives and toward a more holistic definition. Journal of Business Ethics, 151, 627-649.

Vergauwe, J., Hofmans, J., Wille, B., Decuyper, M., \& De Fruyt, F. (2021). Psychopathy and leadership effectiveness: Conceptualizing and testing three models of successful psychopathy. The Leadership Quarterly, https://doi.org/10.1016/j.leaqua.2021.101536

Winn, G. L., \& Dykes, A. C. (2019). Identifying toxic leadership \& building worker resilience. Professional Safety Journal, March, $38-45$. 